\title{
A prospective trial of adjuvant therapy for high-risk uveal melanoma: assessing 5-year survival outcomes
}

\author{
Elaine Binkley (D) , ${ }^{1}$ Pierre L Triozzi, ${ }^{1,2}$ Lisa Rybicki, ${ }^{3}$ Susan Achberger, ${ }^{3}$ Wayne Aldrich, ${ }^{3}$ \\ Arun Singh (D) 1
}

'Department of Ophthalmic Oncology, Cleveland Clinic, Cole Eye Institute, Cleveland, Ohio, USA

${ }^{2}$ Department of Hematology Oncolgy, Wake Forest University, Winston Salem, North Carolina, USA

${ }^{3}$ Department of Ophthalmic Oncology, Taussig Cancer Institute, Cleveland Clinic Foundation, Cleveland, Ohio, USA

\section{Correspondence to}

Dr Arun Singh, Department of Ophthalmic Oncology, Cole Eye Institute, Cleveland Clinic Foundation, Cleveland, $\mathrm{OH}$ 44106, USA; singha@ccf.org

Received 22 April 2019 Revised 3 July 2019 Accepted 6 July 2019 Published Online First 1 August 2019
Check for updates

(C) Author(s) (or their employer(s)) 2020. No commercial re-use. See rights and permissions. Published by BMJ.

To cite: Binkley E, Triozzi PL, Rybicki L, et al.

Br J Ophthalmol

2020:104:524-528

\section{ABSTRACT \\ Background/aims Survival after diagnosis of} metastasis from uveal melanoma is poor. Identifying individuals at high risk for metastasis and developing adjuvant therapy to prevent clinically apparent metastasis could improve survival. We conducted an adjuvant trial of sequential, low-dose dacarbazine (DTIC) and interferon-alpha-2b (IFN- $\alpha-2 b$ ) in patients with cytogenetic high-risk uveal melanoma.

Methods Patients diagnosed with iris, ciliary body or choroidal melanoma with high-risk tumour cytogenetics (monosomy 3) were offered adjuvant treatment with low-dose DTIC and IFN- $\alpha-2 b$ following primary therapy. Eligible but not enrolled patients were observed for comparison. DTIC was administered at $850 \mathrm{mg} /$ $\mathrm{m}^{2}$ intravenously on days 1 and 28 . IFN- $\alpha-2$ b was administered at 3 million units three times a week subcutaneously for 24 weeks beginning at week 9 . Hepatic imaging was performed prior to adjuvant therapy and then at least every 6 months. Survival data were collected for 5 years after enrolment.

Results 33 patients (22\%) were enrolled (treatment group), 29 (19\%) were eligible but did not enrol (observation group) and 88 (59\%) were not eligible. The 5-year metastasis-free survival (MFS) was $64 \% \pm 9 \%$ for treated and $33 \% \pm 10 \%$ for observed patients $(p=0.05)$. The 5 -year overall survival (OS) rate was $66 \% \pm 9 \%$ for treated and $37 \% \pm 10 \%$ for observed patients $(p=0.02)$. Conclusions When adjusted for differences in age, tumour size and initial treatment, survival between treated and observed patients was no longer significant $(p=0.56$ MFS and $p=0.92$ OS). Differences in baseline tumour characteristics between treated and observed patients can influence interpretation of results. Trial registration number NCT01100528.

\section{INTRODUCTION}

While advances in local therapy for uveal melanoma have resulted in a $95 \%$ or greater local tumour control rate, the development of metastatic disease following primary treatment remains a challenge. ${ }^{12}$ Only $2.1 \%$ of patients with uveal melanoma present with metastatic disease at the time of diagnosis of their primary tumour. ${ }^{3}$ However, longitudinal follow-up from the Collaborative Ocular Melanoma Study showed that $34 \%$ of patients will develop metastatic disease within 10 years. $^{3}{ }^{4}$ Survival after diagnosis of metastatic disease is poor, with $80 \%$ of patients dying within 1 year of diagnosis of metastasis. ${ }^{4}$ Moreover, data derived from the Surveillance, Epidemiology, and End Results database indicate a lack of improvement in survival of patients with uveal melanoma between 1973 and 2013. ${ }^{5}$

Multiple lines of evidence suggest that micrometastatic disease likely occurs early in the disease course. ${ }^{67}$ Up to $18 \%$ of patients with uveal melanoma without clinical evidence of metastatic disease may have histopathological evidence of metastasis at autopsy. ${ }^{8}$ Proposed mechanisms by which tumour cells may remain dormant have included immunologic variables, angiogenic factors and tumour cell quiescence models.

In the present era, neither chemotherapy, immunotherapy, nor small-molecule biologics have been shown to improve survival in patients with metastatic uveal melanoma.' Therefore, identifying patients at high risk for metastatic disease at presentation and treating such individuals with adjuvant therapy to prevent the development of clinically apparent metastasis has the potential to improve survival.

Both dacarbazine (DTIC) and interferon-alpha $($ IFN- $\alpha$ ) have shown efficacy in the treatment of metastatic uveal melanoma in murine models. ${ }^{10-12}$ Given that IFN- $\alpha$ exerts anti-tumour activity through its actions on natural killer cells in addition to other immune effectors, and that DTIC can sensitise tumours to immune effectors, these agents may work synergistically to prevent the development of clinically apparent metastatic disease. ${ }^{13} 14$ A meta-analysis of $>3000$ patients concluded that the combination of DTIC plus IFN- $\alpha$ produced a response rate $53 \%$ greater (95\% CI: 1.10 to 2.13$)$ than that seen with DTIC alone. ${ }^{15}$ Such a combination therapy could be effective in the adjuvant setting that is supported by a trial reported by Stadler et al involving 252 patients with cutaneous melanoma. ${ }^{12}$ Patients randomised to 6 months of sequential low-dose regimen of DTIC followed by IFN- $\alpha$ after surgery manifested a reduction of melanoma-associated deaths compared with those randomised to no systemic treatment, ${ }^{12}$ but a concurrent, DTIC-IFN- $\alpha$ regimen was not effective. ${ }^{12} 16$

Hence, we chose sequential low-dose DTIC and interferon-alpha-2b (IFN- $\alpha-2 b$ ) as adjuvant therapy for uveal in patients that had high-risk tumour cytogenetics. Herein, we present 5-year survival outcomes of patients enrolled in an adjuvant therapy open label phase II study.

\section{MATERIALS AND METHODS}

\section{Patients and treatment}

This trial was conducted in parallel with a trial of prognostic fine-needle aspiration biopsy which has been previously published. ${ }^{17}$ In all, 150 consecutive 


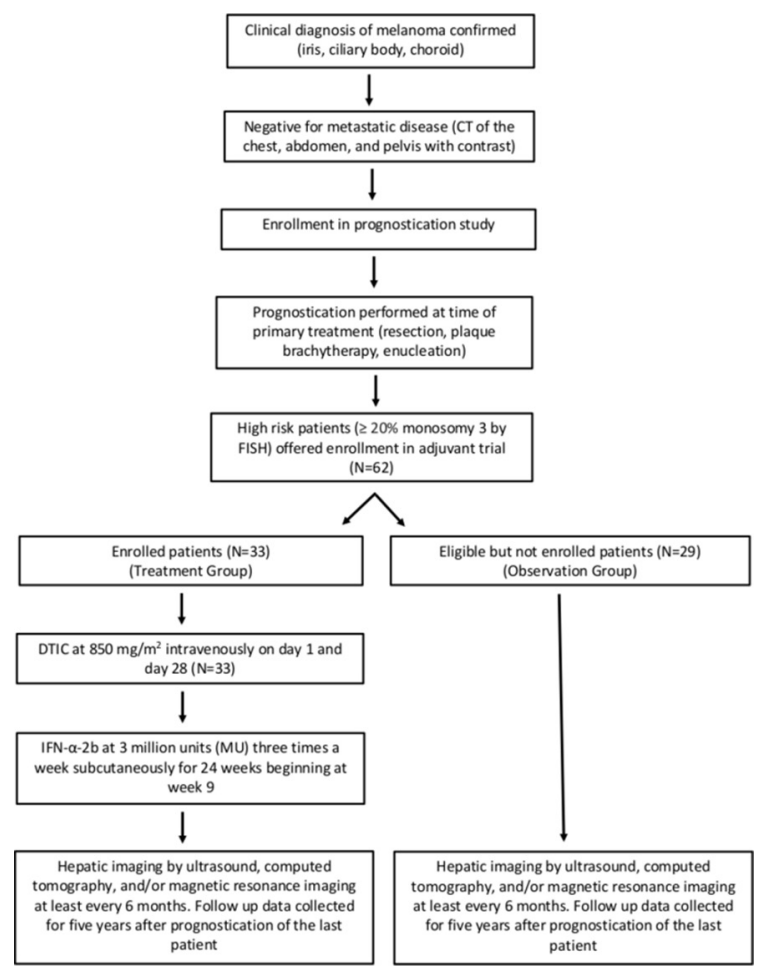

Figure 1 Study design of adjuvant therapy trial of DTIC and IFN$\alpha-2 b$ in patients with uveal melanoma and high-risk cytogenetics. Patients with a clinical diagnosis of choroidal melanoma (iris, ciliary body and choroid) were offered enrolment in a parallel prognostication study following a negative baseline metastatic evaluation. High-risk patients ( $\geq 20 \%$ monosomy 3 ) were offered enrolment in the adjuvant therapy trial with treatment with DTIC and IFN- $\alpha-2 b$ per protocol. In all, 33 patients enrolled in the trial (treatment group) and 29 eligible patients did not enrol (observation group). Both groups of patients were followed with hepatic imaging at least 6 month intervals for 5 years after prognostication of the last patient. DTIC, dacarbazine;IFN- $\alpha-2 b$, interferon-alpha- $2 \mathrm{~b}$.

patients with a clinical diagnosis of uveal melanoma were enrolled in the prognostication study. Clinical diagnosis of melanoma was confirmed using slit lamp examination, gonioscopy, indirect ophthalmoscopy (where indicated) and with ancillary imaging as previously described. ${ }^{17}$ American Joint Committee on Cancer (AJCC) stage was calculated for each patient based on tumour clinical parameters. Fine-needle aspiration biopsy using a transcorneal, trans-scleral or transvitreal approach was performed depending on the location of the tumour. ${ }^{17}$ Cytology was performed for diagnosis in each case and where there was sufficient cellularity, the chromosome 3 status was assessed by fluorescent in situ hybridisation with directly labelled SpectrumGreen and SpectrumOrange enumeration probes for the alphacentromeric locus of chromosome 3 and a locus-specific probe, 3 p26 (TelVysion 3 p, Abbott Molecular Vysis, Des Plaines, IL, USA). ${ }^{17} 18$ In all, 200 interphase cells were scored to determine the percentage of signals per locus. ${ }^{17}$ Based on previous studies, a cut-off of monosomy 3 in $\geq 20 \%$ of cells was used to define high-risk tumour cytogenetics. ${ }^{19} 20$

\section{Inclusion criteria}

Patients with high-risk tumour cytogenetics (monosomy $3 \geq 20 \%$ of cells), adequate primary therapy (enucleation, brachytherapy or resection), negative baseline systemic staging with CT scan of

\begin{tabular}{|c|c|c|c|}
\hline & $\begin{array}{l}\text { Enrolled ( } n=33 \text { ) } \\
\mathrm{N}(\%) \text { or median } \\
\text { (range) }\end{array}$ & $\begin{array}{l}\text { Not enrolled } \\
(\mathrm{n}=29) \\
\mathrm{N}(\%) \text { or median } \\
\text { (range) }\end{array}$ & $P$ value \\
\hline \multicolumn{4}{|l|}{ Sex } \\
\hline Male & $16(48 \%)$ & $15(52 \%)$ & \\
\hline Female & $17(52 \%)$ & $14(48 \%)$ & 1.0 \\
\hline \multicolumn{4}{|l|}{ Age (years) } \\
\hline & $59(20-77)$ & 73 (48-91) & 0.0002 \\
\hline \multicolumn{4}{|l|}{ Involved eye } \\
\hline Right & $19(58 \%)$ & $15(52 \%)$ & 0.80 \\
\hline Left & $14(42 \%)$ & $14(48 \%)$ & \\
\hline \multicolumn{4}{|l|}{ Tumour location } \\
\hline Choroid only & $24(73 \%)$ & 17 (59\%) & \\
\hline Ciliary body \pm choroid/iris & $7(21 \%)$ & $12(41 \%)$ & \\
\hline Iris only & $2(6 \%)$ & 0 & 0.12 \\
\hline \multicolumn{4}{|l|}{$\begin{array}{l}\text { Diameter of tumour base } \\
(\mathrm{mm})\end{array}$} \\
\hline & $13.0(3.0-24.0)$ & $16.0(2.4-25.0)$ & 0.04 \\
\hline \multicolumn{4}{|l|}{ Initial treatment } \\
\hline Enucleation & $11(33 \%)$ & $17(59 \%)$ & \\
\hline Plaque brachytherapy & $20(61 \%)$ & $12(41 \%)$ & \\
\hline Local resection & $2(6 \%)$ & 0 & 0.08 \\
\hline
\end{tabular}

the chest, abdomen and pelvis with contrast, performance status (Eastern Cooperartive Oncology Group) less than 2 and normal organ function were offered enrolment in the adjuvant therapy trial. Patients had to be entered within 56 days of completing primary therapy. DTIC was administered at $850 \mathrm{mg} / \mathrm{m}^{2}$ intravenously on day 1 and day 28 . IFN- $\alpha-2 b$ was administered at 3 million units (MU) three times a week subcutaneously for 24 weeks beginning at week 9. Toxicity was graded using National Cancer Institute Common Toxicity Criteria (Version 2.0). With the exception of haematologic toxicity, dosing was held and modified for grade 3 or 4 toxicities. IFN- $\alpha-2 b$ was withheld for Grade 4 neutropenia, that is, absolute neutrophil count $(\mathrm{ANC})<500 / \mathrm{mm}^{3}$, and restarted at $1.5 \mathrm{MU}$ when $\mathrm{ANC} \geq 1000 /$ $\mathrm{mm}^{3}$. Baseline staging was done with CT and subsequent surveillance (every 6 months) with by hepatic ultrasonography as per standard of clinical practice. ${ }^{21}$ Any suspicious findings on liver ultrasonography were confirmed by hepatic CT/MRI prior to liver biopsy. Follow-up data were collected for 5 years after enrolment of the last patient in the trial (figure 1).

\section{Statistical analysis}

Study sample size

Precher et al reported a 3-year metastasis-free survival (MFS) rate for patients with monosomy 3 of $50 \% .^{22}$ This translates to a 2 -year rate of $63 \%$ with an assumption that MFS follows an exponential distribution. For the purposes of this clinical trial, treatment would be considered ineffective if the 2-year MFS was $<60 \%$, and the combination would be considered promising if the MFS was $>80 \%$.

\section{Statistical power analysis}

Based on the current status of accrual at our institution, it was estimated that over 3 years, a maximum of 36 eligible and evaluable patients would be needed to provide $>80 \%$ power to detect 

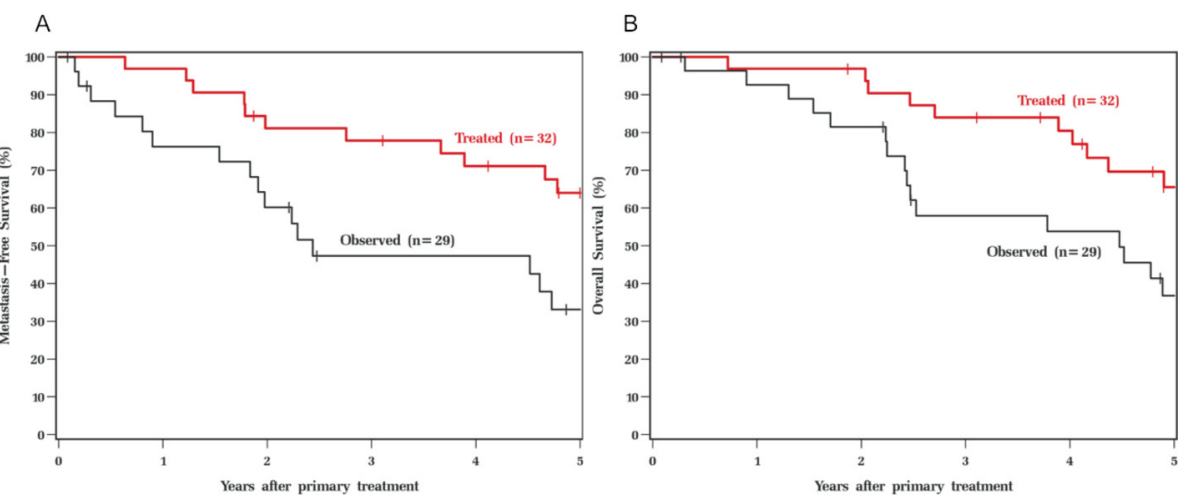

Figure 2 Metastasis-free (A) and overall survival (B) of treated and observed patients. In univariable analysis, treated patients had improved and metastasis-free survival (A) and overall survival (B) compared with observed patients.

an increase in the 2-year MFS from $60 \%$ to $80 \%$ base on a twosided test with a type 1 error of 0.05

\section{Analysis}

Data were summarised as frequency counts and percentages (categorical variables) or median and range (continuous variables). Baseline characteristics were compared between treated and observed patients with $\chi^{2}$ test, Fisher's exact test or Wilcoxon rank sum test. MFS was defined as the time from primary therapy to the first sign of metastatic disease or death from any cause; patients who were alive without disease at last follow-up were censored. Overall survival (OS) was calculated from the date of primary treatment to the date of death from any cause; patients who were alive at last follow-up were censored. Both outcomes were estimated with the method of KaplanMeier and compared between treated and observed patients with the log-rank test. Five-year estimates of MFS and OS are presented with 95\% CIs. Cox proportional hazards analysis was used to assess the effect of treatment versus observation on MFS and OS after adjusting for other prognostic factors. Candidate adjustment factors included gender, age, involved eye, tumour location, monosomy 3, tumour diameter and initial treatment. Results were summarised as HR and 95\% CI. All statistical analyses were performed using SAS software V.9.4 (SAS Institute, Cary, NC, USA).

\section{RESULTS}

In all, 150 patients were enrolled in the prognostication trial. Of these patients, 33 patients with high-risk cytogenetics (22\%) enrolled in the adjuvant therapy trial (treatment group), 29 (19\%) were eligible for the trial but did not enrol (observation group) and 88 (59\%) with low-risk cytogenetics were not eligible for the trial (figure 1). Overall, among 62 eligible patients with high-risk cytogenetics, $50 \%$ were men, median age at initial surgery was 64 years (range: 20-91), and 66\% had choroidal tumours. The median tumour diameter was $14.5 \mathrm{~mm}$ (range: 2.4-25.0) and AJCC stage was distributed fairly evenly (18\% stage $1,29 \%$ stage $2,24 \%$ stage 3 and $18 \%$ stage 4 ). Initial treatment was plaque brachytherapy in 52\%, enucleation in $45 \%$ and local resection in 3\% (table 1).

Patients in the treatment and observation groups differed with respect to age, basal tumour diameter and AJCC stage with treated patients being younger (median age 59 vs 73 years, $\mathrm{p}=0.0002$ ), having smaller tumours (median basal diameter 13.0 vs $16.0 \mathrm{~mm}, \mathrm{p}=0.04)$ and lower AJCC stage $(p=0.03)$ when compared with observed patients (table 1 ).
Therapy was well tolerated. All treated patients received the prescribed doses of DTIC and IFN- $\alpha-2 b$. Grade 1 or 2 fatigue, reported by 33 patients (87\%), was most common. Grade 1 or 2 elevations in hepatic transaminases were observed in 14 patients (37\%), and grade 1 or 2 depression, in five patients (13\%). Grade-3 haematological toxicity was observed in six patients while on IFN- $\alpha-2 b$ that was dose-limiting. No grade 4 adverse events were reported. Ocular toxicities were not observed.

One patient was lost to follow-up and was not included in calculations of MFS or OS. Among 28 patients who were alive and metastasis-free, median follow-up was 62 months (range: 1-86), with 79\% having at least 4 years and 64\% having at least 5 years of follow-up. In univariable Cox analysis, observed patients had worse MFS (HR: 2.10, CI: 1.00 to 4.41, p=0.05) and OS (HR: 2.41, 95\% CI: 1.13 to $5.16, \mathrm{p}=0.02$ ) relative to treated patients. Five-year and median MFS were 64\% (44-78) and 79 months in treated patients and 33\% (15-52) and 29 months in observed patients (figure 2A). Five-year median OS was 66\% (45-80, median not observed) in treated patients and $37 \%$ (19-55, median 54 months) in observed patients (figure 2B).

On multivariable analysis, using factors identified to be significant by univariate analysis (table 1 ), age and initial treatment modality were independent predictors of MFS and age and tumour diameter were independent predictors of OS; treatment versus observation was not significant for either outcome. When treatment versus observation was added to these models, the observed difference in MFS and OS between the groups was no longer significant $(p=0.56$ and $p=0.92$, respectively) (table 2).

\begin{tabular}{llll}
\hline $\begin{array}{l}\text { Table } 2 \\
\text { survival }\end{array}$ & Multivariable analysis of metastasis-free and overall & \\
\hline Survival & HR & $95 \% \mathrm{Cl}$ & P value \\
\hline $\begin{array}{l}\text { Metastasis-free survival } \\
\quad \text { Observed versus treated }\end{array}$ & 1.27 & 0.56 to 2.90 & 0.56 \\
$\quad$ Age (10-year increase) & 1.35 & 0.98 to 1.87 & 0.07 \\
$\quad$ Initial treatment (enucleation vs other) & 3.83 & 1.79 to 8.18 & $<0.001$ \\
$\begin{array}{l}\text { Overall survival } \\
\quad \text { Observed versus treated }\end{array}$ & 1.04 & 0.44 to 2.47 & 0.92 \\
$\quad$ Age (10-year increase) & 1.59 & 1.10 to 2.30 & 0.013 \\
\hline Tumour basal diameter (1 mm increase) & 1.18 & 1.07 to 1.31 & 0.001 \\
\hline
\end{tabular}


Table 3 Published risk stratified adjuvant therapy trials for uveal melanoma using molecular techniques

\begin{tabular}{|c|c|c|c|c|c|}
\hline Study & Design & Inclusion criteria & Enrolment $(\mathrm{N})$ & Median follow-up & Outcomes \\
\hline $\begin{array}{l}\text { Adjuvant dendritic cell } \\
\text { vaccination in high-risk uveal } \\
\text { melanoma (Bol et al 2016) }\end{array}$ & Non-randomised phase II clinical trial & $\begin{array}{l}\text { High-risk chromosome status } \\
\text { (monosomy 3) }\end{array}$ & $\begin{array}{l}23 \text { patients completed at } \\
\text { least one cycle, } 18 \text { patients } \\
\text { completed all three vaccination } \\
\text { cycles }\end{array}$ & Not reported & $\begin{array}{l}\text { Median DFS } 34.5 \text { months } \\
(95 \% \mathrm{Cl}: 27.2 \text { to } 41.8) \\
\text { Median OS } 51.8 \text { months } \\
(95 \% \mathrm{Cl}: 42.1 \text { to } 62.7)\end{array}$ \\
\hline $\begin{array}{l}\text { Adjuvant sunitinib in high-risk } \\
\text { patients with uveal melanoma } \\
\text { (Valsecchi et al 2018) }\end{array}$ & Retrospective cohort study & $\begin{array}{l}\text { 1) High-risk chromosome } \\
\text { status (monosomy } 3 \text { and } 8 q \\
\text { amplification) or GEP class two or } \\
\text { (2) high-risk chromosome status } \\
\text { (monosomy 3) and large tumour } \\
\text { size (T3-4 AJCC) }\end{array}$ & 128 (54 treated patients) & $\begin{array}{l}\text { Median } 52.7 \text { months (range: } \\
0.26-108 \text { months) }\end{array}$ & $\begin{array}{l}\text { Median PFS-treated patients } \\
58.6 \text { months ( } 95 \% \text { Cl: } 33.1 \\
\text { to } 84.1 \text { ) } \\
\text { 5-year OS probability } \\
\text { Sunitinib } 0.75 \text { ( } 95 \% \text { Cl: } 0.59 \\
\text { to } 0.85 \text { ) } \\
\text { No sunitinib } 0.55 \text { ( } 95 \% \text { Cl } 0.43 \\
\text { to } 0.66 \text { ) }\end{array}$ \\
\hline $\begin{array}{l}\text { A prospective trial of adjuvant } \\
\text { therapy for high-risk uveal } \\
\text { melanoma: assessing } 5 \text {-year } \\
\text { survival outcomes (present } \\
\text { study) }\end{array}$ & $\begin{array}{l}\text { Non-randomised prospective clinical } \\
\text { trial }\end{array}$ & $\begin{array}{l}\text { High-risk chromosome status } \\
\text { (monosomy 3) }\end{array}$ & 150 (33 treated patients) & $\begin{array}{l}\text { Median (for metastasis-free } \\
\text { patients still being followed) } \\
63.9 \text { months (range: } 1.0-97.5 \text { ) }\end{array}$ & $\begin{array}{l}5 \text {-year MFS enrolled } 64 \% \pm 9 \% \text {, } \\
\text { not enrolled } 33 \% \pm 10 \% \\
5 \text {-year OS } 66 \% \pm 9 \% \text { enrolled, } \\
37 \% \pm 10 \% \text { not enrolled }\end{array}$ \\
\hline
\end{tabular}

AJCC, American Joint Committee on Cancer; DFS, disease-free survival; GEP, gene expression profiling; MFS, metastasis-free survival; OS, overall survival; PFS, progression-free survival.

\section{DISCUSSION}

Several published adjuvant studies conducted prior to the development of molecular methods of prognostication have been largely ineffective. ${ }^{23-25}$ Methanol-extract bacilli CalmetteGuerin vaccine, IFN- $\alpha-2 a$, IFN- $\alpha-2 b$, intra-arterial hepatic fotumustine and DTIC monotherapy have been unsuccessful in improving survival in patients at high risk for metastasis, prognosticated based on clinical features. ${ }^{23-27}$

Molecular strategies such as chromosome analysis, multiplex ligation-dependent probe amplification (MLPA) and gene expression profiling (GEP) have now enhanced our ability to accurately prognosticate and identify patients who would benefit the most from adjuvant therapy. ${ }^{28-30}$ There are several trials that are either in progress or were terminated due to lack of accrual. The decision to undergo prognostication test in a disease wherein adjuvant therapy is unavailable or ineffective can be emotionally complex. ${ }^{31}$ Although all patients with high-risk cytogenetics were offered enrolment in this adjuvant trial, only about half of the patients $(47 \%, 29$ of the 62 eligible patients enrolled). In general, several factors such as burden of excessive testing, older age, existing comorbidity, potential drug toxicity and frequent hospital visits can deter patients from prognostication ${ }^{32}$ and/or entering an adjuvant therapy trial. ${ }^{33}$ Given that this was an exploratory study, randomisation was not conducted. If the results were encouraging (positive), a confirmatory randomised study would have been conducted.

Excluding the present study, there are only two published adjuvant therapy trials using cytogenetic molecular risk stratification as inclusion criteria (table 3 ). ${ }^{3435}$ A recent retrospective cohort study of the tyrosine kinase inhibitor sunitinib in highrisk patients as defined by tumour monosomy 3 and $8 \mathrm{q}$ amplification, monosomy 3 and AJCC class 3 or 4, or class 2 GEP profile showed promise in improving survival in patients with high-risk tumours. ${ }^{35}$ However, the patients in the treated group were both younger and with smaller tumours than the institutional controls used for comparison in the study. ${ }^{35}$

While the findings of our study indicate that low-dose DTIC and IFN- $\alpha-2 b$ therapy does not appear to be effective at reducing MFS or OS, these findings remain important given that they highlight the role that clinical features play in determining metastatic risk and therefore these variables must be carefully considered when interpreting the results of non-randomised adjuvant therapy trials when not matched for baseline prognostic characteristics. While there did initially appear to be a statistically significant improvement in MFS and OS, these differences were no longer significant after accounting for differences in age and tumour size. Larger tumours were more likely to be treated with enucleation rather than globe sparing therapy likely accounting for the difference in outcomes based on initial treatment modality. Patients in the treatment group had smaller tumours and were younger than patients in the observation group despite having similar high-risk tumour cytogenetics.

Although molecular methods of prognostication including tumour chromosome analysis and GEP testing provide validated methods prognostication for patients with uveal melanoma, incorporation of tumour size seems to enhance overall prognostication. ${ }^{28} 3036$ Dogrusoz et al showed AJCC size criteria for prognosis were enhanced by the addition of tumour chromosome analysis. ${ }^{36}$ The findings of the present study support the need to consider both clinical and molecular data when designing and interpreting the results of adjuvant therapy trials.

As with any therapeutic trial of a rare disease, the number of patients treated in this study were relatively small $(n=33)$. While there was no statistically significant improvement in survival after 5 years between treated and observed patients when adjusted for the variables described above, it is possible that with an increased number of patients, a significant treatment effect may have been observed.

In summary, we did not find a significant improvement in 5 -year survival outcomes in patients with uveal melanoma with high-risk cytogenetics who were treated with adjuvant low-dose DTIC and IFN- $\alpha-2 b$. These data highlight the importance of considering both clinical and molecular data when designing and assessing outcomes in adjuvant therapy trials for uveal melanoma.

Contributors EB: Data interpretation, drafting, critical revision manuscript. PLT: Study design, data acquisition, data interpretation, drafting manuscript. LR: Data analysis and interpretation, critical revision of manuscript. SA: Data analysis and interpretation. WA: Data analysis and interpretation. AS: Study design, data acquisition, data interpretation, drafting and critical revision of manuscript.

Funding The authors have not declared a specific grant for this research from any funding agency in the public, commercial or not-for-profit sectors.

Competing interests None declared.

Patient consent for publication Obtained.

Ethics approval This study was approved by the Institutional Review Board (IRB) at the Cleveland Clinic and Case Comprehensive Cancer Centre (note that the study was conducted at the Taussig Cancer Centre at the Cleveland Clinic, there is a combined IRB for the cancer centres at the Cleveland Clinic and Case Western Reserve University). 
Provenance and peer review Not commissioned; externally peer reviewed.

\section{ORCID iDs}

Elaine Binkley http://orcid.org/0000-0003-0464-3372

Arun Singh http://orcid.org/0000-0001-9411-0320

\section{REFERENCES}

1 Harbour JW, Murray TG, Byrne SF, et al. Intraoperative echographic localization of iodine 125 episcleral radioactive plaques for posterior uveal melanoma. Retina 1996;16:129-34.

2 Gragoudas ES, Egan KM, Seddon JM, et al. Intraocular recurrence of uveal melanoma after proton beam irradiation. Ophthalmology 1992;99:760-6.

3 Freton A, Chin KJ, Raut R, et al. Initial PET/CT staging for choroidal melanoma: AJCC correlation and second nonocular primaries in 333 patients. Eur J Ophthalmol 2012;22:236-43.

4 Diener-West M, Reynolds SM, Agugliaro DJ, et al. Development of metastatic disease after enrollment in the COMS trials for treatment of choroidal melanoma: collaborative ocular melanoma Study Group report No. 26. Arch Ophthalmol 2005; 123:1639-43.

5 Aronow ME, Topham AK, Singh AD. Uveal melanoma: 5-year update on incidence, treatment, and survival (seer 1973-2013). Ocul Oncol Pathol 2018:4:145-51.

6 Grossniklaus HE. Progression of ocular melanoma metastasis to the liver: the 2012 Zimmerman lecture. JAMA Ophthalmol 2013:131:462-9.

7 Borthwick NJ, Thombs J, Polak M, et al. The biology of micrometastases from uveal melanoma. J Clin Pathol 2011;64:666-71.

8 Kujala E, Mäkitie T, Kivelä T. Very long-term prognosis of patients with malignant uveal melanoma. Invest Ophthalmol Vis Sci 2003:44:4651-9.

9 Carvajal RD, Schwartz GK, Tezel T, et al. Metastatic disease from uveal melanoma: treatment options and future prospects. Br J Ophthalmol 2017;101:38-44.

10 Niederkorn JY, Sanborn GE, Gamel JW. Suicide enzyme inhibition as a chemotherapeutic strategy for controlling metastases derived from intraocular melanomas. Invest Ophthalmol Vis Sci 1987;28:1844-50.

11 Dithmar S, Rusciano D, Lynn MJ, et al. Neoadjuvant interferon alfa-2b treatment in a murine model for metastatic ocular melanoma: a preliminary study. Arch Ophthalmol 2000;118:1085-9.

12 Stadler R, Luger T, Bieber T, et al. Long-Term survival benefit after adjuvant treatment of cutaneous melanoma with dacarbazine and low dose natural interferon alpha: a controlled, randomised multicentre trial. Acta Oncol 2006:45:389-99.

13 Tarhini AA, Gogas H, Kirkwood JM. IFN- $\alpha$ in the treatment of melanoma. J Immunol 2012:189:3789-93.

14 Wack C, Kirst A, Becker J, et al. Chemoimmunotherapy for melanoma with dacarbazine and 2,4-dinitrochlorobenzene elicits a specific T cell-dependent immune response. Can Immunol Immunother 2002;51:431-9.

15 Huncharek M, Caubet JF, McGarry R. Single-Agent DTIC versus combination chemotherapy with or without immunotherapy in metastatic melanoma: a metaanalysis of 3273 patients from 20 randomized trials. Melanoma Res 2001:11:75-81.

16 Garbe C, Radny P, Linse R, et al. Adjuvant low-dose interferon \{alpha\}2a with or without dacarbazine compared with surgery alone: a prospective-randomized phase
III DeCOG trial in melanoma patients with regional lymph node metastasis. Ann Oncol 2008:19:1195-201.

17 Singh AD, Medina CA, Singh N, et al. Fine-Needle aspiration biopsy of uveal melanoma: outcomes and complications. Br J Ophthalmol 2016;100:456-62.

18 Frater JL, Tsiftsakis EK, Hsi ED, et al. Use of novel $t(11 ; 14)$ and $t(14 ; 18)$ dual-fusion fluorescence in situ hybridization probes in the differential diagnosis of lymphomas of small lymphocytes. Diagn Mol Pathol 2001;10:214-22.

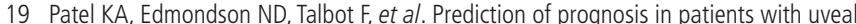
melanoma using fluorescence in situ hybridisation. Br J Ophthalmol 2001;85:1440-4.

20 Aronow M, Sun Y, Saunthararajah Y, et al. Monosomy 3 by fish in uveal melanoma: variability in techniques and results. Surv Ophthalmol 2012;57:463-73.

21 Choudhary MM, Gupta A, Bena J, et al. Hepatic ultrasonography for surveillance in patients with uveal melanoma. JAMA Ophthalmol 2016:134:174-80.

22 Prescher $\mathrm{G}$, Bornfeld $\mathrm{N}$, Hirche $\mathrm{H}$, et al. Prognostic implications of monosomy 3 in uveal melanoma. Lancet 1996:347:1222-5.

23 McLean IW, Berd D, Mastrangelo MJ, et al. A randomized study of methanol-extraction residue of Bacille Calmette-Guerin as postsurgical adjuvant therapy of uveal melanoma. Am J Ophthalmol 1990;110:522-6.

24 Lane AM, Egan KM, Harmon D, et al. Adjuvant interferon therapy for patients with uveal melanoma at high risk of metastasis. Ophthalmology 2009;116:2206-12.

25 Desjardins LDT, Levy C, Cojean I, et al. Etude randomisée de chimiothérapie adjuvante PAR Le Déticène dans Le mélanome choroïdien. Ophtalmologie 1998;12:168-73.

26 Voelter V, Schalenbourg A, Pampallona S, et al. Adjuvant intra-arterial hepatic fotemustine for high-risk uveal melanoma patients. Melanoma Res 2008:18:220-4.

27 Richtig E, Langmann G, Schlemmer G, et al. [Safety and efficacy of interferon alfa-2b in the adjuvant treatment of uveal melanomal. Ophthalmologe 2006:103:506-11.

28 Shields CL, Ganguly A, Bianciotto CG, et al. Prognosis of uveal melanoma in 500 cases using genetic testing of fine-needle aspiration biopsy specimens. Ophthalmology 2011;118:396-401.

29 Damato B, Dopierala J, Klaasen A, et al. Multiplex ligation-dependent probe amplification of uveal melanoma: correlation with metastatic death. Invest Ophthalmol Vis Sci 2009;50:3048-55.

30 Harbour JW. A prognostic test to predict the risk of metastasis in uveal melanoma based on a 15-gene expression profile. Methods Mol Biol 2014;1102:427-40.

31 Schuermeyer I, Maican A, Sharp R, et al. Depression, anxiety, and regret before and after testing to estimate uveal melanoma prognosis. JAMA Ophthalmol 2016;134:51-6.

32 Davanzo JM, Binkley EM, Bena JF, et al. Risk-Stratified systemic surveillance in uveal melanoma. Br J Ophthalmol 2019:103:1868-71.

33 Denicoff AM, McCaskill-Stevens W, Grubbs SS, et al. The National cancer InstituteAmerican Society of clinical oncology cancer trial Accrual symposium: summary and recommendations. J Oncol Pract 2013;9:267-76.

34 Bol KF, van den Bosch T, Schreibelt G, et al. Adjuvant dendritic cell vaccination in highrisk uveal melanoma. Ophthalmology 2016;123:2265-7.

35 Valsecchi ME, Orloff M, Sato R, et al. Adjuvant sunitinib in high-risk patients with uveal melanoma: comparison with institutional controls. Ophthalmology 2018;125:210-7

36 Dogrusöz M, Bagger M, van Duinen SG, et al. The prognostic value of AJCC staging in uveal melanoma is enhanced by adding chromosome 3 and $8 q$ status. Invest Ophthalmol Vis Sci 2017;58:833-42. 